\title{
A BIBLIOTECA EM RUÍNAS
}

\author{
MARIA ANGÉLICA MELENDI mostra como coleções de livros são \\ trabalhadas pelas artes visuais na atualidade
}

\author{
In omnibus requiem quaesivi, et nunquam inveni nisi in angulo cum \\ libro. [1] \\ Tomasso da Kempis \\ E venham, pois, os alegres incendiários de dedos carbonizados! Ei-los! Ei- \\ los!... Vamos! Ateiem fogo às estantes das bibliotecas!... \\ Filippo Tommaso Marinetti
}

\section{Dois studiolos}

Por volta de 1475, Antonello da Messina concluiu a obra que representa "São Jerônimo no seu estúdio" e que hoje está na National Gallery de Londres. O pequeno quadro $(45.7 \times 36.2 \mathrm{~cm})$ nos deixa ver, como se fosse pela abertura de uma janela em arco de estilo catalão, o gabinete do Santo, a quem supomos concentrado na tradução da Bíblia para o latim.

Sob as altas abóbadas de uma catedral, o estúdio de madeira simples ocupa o centro da cena e se apoia sobre uma base com três degraus. São Jerônimo lê um livro, outros _a maior parte deles entreabertos_ espalham-se sobre a mesa ou se enfileiram nas estantes.

Das janelas superiores do edifício se veem pássaros revoando num céu sem nuvens. Através das do térreo, vislumbra-se um palácio branco em meio a uma campina verdejante por onde passeiam cavaleiros, outros dois homens cruzam o rio numa embarcação, enquanto um par de amas de toucas brancas brincam com os cães. Não faltam ciprestes, galinhas e juncos à beira da água.

Mas Jerônimo, que deixou seus tamancos ao pé dos degraus, está concentrado em sua leitura, iluminado por um feixe de luz que atravessa 
a penumbra, roça seu rosto e cai sobre as páginas do livro.

O estúdio contém também outros objetos sobre o chão: a cadeira românica, uma arca de madeira sobre a que se pousa o chapéu cardinalício, um par de vasos de louça com plantas, um delicado gatinho. Há uma nota manuscrita fincada no lado do scriptorium e, nas estantes, uma bilha de porcelana, um copo, algumas caixas e bandejas, umas chaves. Pela direita, do canto mais escuro do templo se aproxima o leão a quem Jerônimo tirou o espinho do pé e que agora é seu amigo. No limiar da porta, sobre a pedra ocre, um pavão e uma perdiz olham para lados opostos[2].

Jorge Luis Borges publicou em 1945 o conto El Aleph, na revista Sur. Não me interessa aqui o vão amor da personagem Borges pela obscena Beatriz Viterbo, nem a existência de um (falso) Aleph no subsolo da casa da rua Garay. Sempre me intrigou, neste conto perfeito, a personagem de Carlos Argentino Daneri, o rival de Borges, seu doppelganger[3]. Daneri, um escritor pomposo e medíocre, primo e amante de Beatriz, que cria versos vulgares (e que, apesar de tudo, são borgianos); Daneri menosprezado pelo protagonista, que apesar disso o visita com frequência. Esse Daneri (de nome tão italiano, de estirpe tão arrivista que tem Argentino como nome de batismo) empreende um elogio do homem moderno:

\footnotetext{
_Lo evoco _dijo con una admiración algo inexplicable_en su gabinete de estudio, como si dijéramos en la torre albarrana de una ciudad, provisto de teléfonos, de telégrafos, de fonógrafos, de aparatos de radiotelefonía, de cinematógrafos, de linternas mágicas, de glosarios, de horarios, de prontuarios, de boletines...[4]
}

A observação de Daneri_de Borges_, que Borges despreza, parece descrever um escritório atual, ou, ainda, um estúdio futuro. Persistindo em seu delírio, Carlos Argentino observara que, para um homem assim, viajar seria inútil; o século XX subvertera fábula de Maomé e a montanha: as montanhas, agora, acudiriam ao moderno Maomé.

Do studiolo de São Jerônimo ao gabinete do "homem moderno", 
passaram-se vários séculos. Se o do tradutor da Bíblia fecha-se sob as abóbadas penumbrosas de uma catedral, o do intelectual moderno campeia na torre isolada _albarrã_de uma cidade do futuro.

Escolho estes dois estudos, estas duas bibliotecas ficcionais, porque também me parecem íntimas e silenciosas. Não falarei da Biblioteca de Alexandria que foi incendiada três vezes: a primeira por Júlio César, depois pelos zelotes e, finalmente, pelo primeiro Califa. Não falarei das bibliotecas destruídas pelo fogo a mando de Führers e Duces, de alguns imperadores chineses ou de vários ditadores latino-americanos.

Coleções inteiras foram e serão destruídas para eliminar blasfêmias, para esconder verdades inconvenientes, para persuadir opiniões, para anular memórias candentes. Não falarei de bibliotecas inundadas ou arrasadas pela fúria das intempéries. Não falarei de Babel nem falarei de Mnemosyne.

Minhas duas bibliotecas imaginárias, dois estúdios ou dois escritórios, a que pintou Antonello e a que descreveu Borges (ou seu doppelganger), remetem, ou querem remeter, às bibliotecas particulares, que convivem conosco, às bibliotecas de pequenos bairros, paróquias, sinagogas... As primeiras que se perdem, as que enterramos, as que ocultamos por medo ou por precaução.

\section{BIBLIOTECAS EM RUÍNAS}

Na produção contemporânea das artes visuais vêm aparecendo paulatinamente alusões a essas bibliotecas arruinadas. Às vezes como memoriais, feitos sob demanda, como os trabalhos de Misha Ullman e Rachel Whiteread. Outras surgem aqui ou ali dentro do trabalho de alguns artistas: acontecimentos intermitentes ou repetidos, quase sempre a resgatar recordações, convocar nostalgias ou, ainda, instigar-nos a retomar hábitos perdidos.

Tudo, na biblioteca_as paredes, as estantes, os livros_, está sempre a um passo da ruína. São Jerônimo queixa-se do estado lamentável dos velhos manuscritos, em parte porque o material não resiste à ação do tempo: a proximidade da água e a umidade enegrecem os livros e os destroem[5]. Gyorgy Faludy, citando o famoso romance de Ray Bradbury, também 
teme a fragilidade dos livros:

\author{
... books only last a little time \\ and this one will be borrowed, scarred, \\ burned by Hungarian border guards, \\ lost by the library, broken-backed, \\ its paper dried up, crisped and cracked, \\ worm-eaten, crumbling into dust, \\ or slowly brown and self-combust \\ when climbing Fahrenheit has got \\ to 451 , for that's how hot \\ your town will be when it burns down...[6]
}

Água e fogo ameaçam os livros, mas também traças, ratos e homens. Não cabe aqui se estender sobre os inúmeros relatos desses acontecimentos, nem da equivalência metafórica entre os livros e os humanos.

Novas tecnologias anunciam, também, o fim do livro impresso e com ele o fim da materialidade de um dos objetos mais singulares de nossa civilização. A Biblioteca em ruínas como um topos da segunda metade do século XX parece vir, em primeiro lugar, em decorrência das demandas de memória do fim do século, quando aparece, nos memoriais da Shoah, como identificação dos judeus como "povo do livro", mas também da lembrança traumática da Bücherverbrennung, organizada entre 10 de Maio e 21 de junho de 1933[7], poucos meses depois da chegada ao poder de Adolf Hitler e repetida em outros tempos e outros países ao longo desse século.

Bibliotecas espectrais, as bibliotecas em ruínas são também ruínas do futuro. Nunca chegaram a existir em toda a sua plenitude, mas também nunca chegaram a ruir de fato. Interrompidas, estáticas, paralisadas na sua incompletude preservada, vagando como fantasmas entre o mundo dos vivos e dos mortos, mantêm uma vida em suspensão[8].

\title{
ALGUMAS BIBLIOTECAS
}

Em Bebelplatz, Berlim, em 1995, onde os nazistas queimaram livros em 1933, o artista israelita Micha Ullman criou uma biblioteca subterrânea: 
o Memorial for the book burning. O memorial consiste de uma janela sobre o chão da praça sob a qual aparece uma pequena sala iluminada com estantes vazias. Esse vazio, como o vazio de cada sepultura, nunca se preenche. Quanto mais profunda é a cova, maior o vazio. Na biblioteca sem livros o vazio é palpável; esperamos, em vão, ver o que não está. Uma placa de bronze, ao lado, cita Heinrich Heine: Aqueles que queimam livros acabarão por queimar pessoas.

O Judenplatz Holocaust Memorial, 2000, Viena, de Rachel Whiterad, vulgarmente chamado Biblioteca sem nome (Nameless Library) é um monumento fraguado em concreto cujas paredes são feitas de fileiras de livros. Como uma biblioteca à qual tivessem sido arrancadas as paredes, as páginas dos livros que estariam contra os muros agora se veem do exterior. A massa de concreto que endureceu as páginas também moldou o negativo das portas duplas, fechadas.

Vemos as bordas das capas dos livros, as páginas inutilizadas. Como todo o edifício, os livros de cimento são pálidos sob a luz fria do outono, e pequenas imperfeições sobre a superfície de alguns fazem com que pareçam gastos, usados, descoloridos pelo tempo. A chuva, as intempéries e o tempo mancharão as superfícies da Biblioteca sem nome, aumentando o poder de evocação[9].

À distancia, os livros quase não se veem e o memorial parece ser feito de um empilhamento de placas. O topo da estrutura se corta em ângulo e, mesmo que pareça ecoar nos tetos dos prédios barrocos que rodeiam a praça, a sua volumetria o faz parecer com um bunker, sólido e pesado, subjugado a uma espécie de duração prolongada.

A altura do memorial se afirma contra os prédios vizinhos, mais altos, como uma interrupção ao ritmo edilício. A Biblioteca sem nome não dialoga com a estatua de Gotthold Ephraim Lessing nem com os edifícios que rodeiam a praça, muito menos com os restos de uma sinagoga do século XV que foi descoberta na construção do memorial e que jaz _ruína belamente conservada_num vão subterrâneo, sob a praça. $\mathrm{O}$ Judenplatz Holocaust Memorial, um bloco impenetrável feito de livros silenciados para sempre, é uma rememoração muda e silente que não 
desaparece no esquecimento cotidiano: um lugar onde as memórias acontecem.

Em 2001, Marcelo Brodsky e Eduardo Feller publicaram o vídeo Los condenados de la tierra, um lento percurso pelos livros desenterrados, que saem à luz depois de anos. Um punhado de imagens que mostram livros destruídos sobre uma camada de terra escura; a fértil terra do pampa úmido. Los condenados de la tierra de Franz Fanon, La sociedade industrial contemporánea de Fromm, Gorz, Marcuse e Flores Olea, El llano en llamas de Juan Rulfo, Revolución teórica de Karl Marx; o mofo e a umidade corroem as letras e devoram as capas das velhas edições de Siglo XXI e do Fondo de Cultura Económica. Livros de sociologia, economia, romances: alguns dos livros de uma geração que queria mudar o mundo.

Na Argentina, um casal, entre tantos outros, tinha enterrado vários dos seus livros num jardim da cidade de Mar del Plata, em 1976. Vinte anos mais tarde, seus filhos Leonardo e Javier os procuraram e desenterraram.

\footnotetext{
Esses quatro livros foram enterrados durante a ditadura militar.

Permaneceram sob a terra durante quase vinte anos, no jardim da casa de Nélida Valdez y Oscar Elissamburu, em Mar del Plata. Gozaram de digna sepultura, um privilégio que não tiveram muitas das vítimas da ditadura. Hoje, desenterrados pelos filhos, são um testemunho do que tivemos que passar. [...]Suas folhas, palavras e signos se converteram na memória do que foram e em testemunho resgatado por uma nova geração.[10]
}

No período ditatorial conhecido como El proceso, 1976-1983, uma ditadura militar instaurou, na Argentina, o estado de exceção. O terror implantado por ela fez a todos acreditarem que possuir um livro, uma agenda com nomes e endereços ou qualquer elemento que pudesse nos identificar com a ideologia perseguida poderia se converter na passagem até a tortura e a morte. Muitos se viram obrigados a enterrar seus livros ou deixá-los abandonados nas esquinas, junto com o lixo.

Porém, o sentimento que prevalecia nos que enterraram seus livros era de esperança, não de medo. Não os destruíram nem os queimaram, os 
guardaram para serem recuperados. No momento mais perigoso de suas vidas, essas pessoas intuíram que haveria um tempo em que esses livros poderiam renascer em outras mãos. O vídeo de Brodsky e Feller, breve e singular, exibe o horror da exumação. A umidade, o tempo e as animálias enegreceram e corroeram as páginas amadas.

Anselm Kiefer é um fazedor de livros únicos, como manuscritos medievais. Seus livros não contêm uma história nem uma narrativa ficcional, tampouco poemas. São volumes em cujas páginas o artista coloca fotografias, frases, pinturas feitas com toda a gama dos materiais que ele usa: cinzas, cabelos, unhas, arame de cobre, plantas secas, vidro, chumbo. The High Priestess / Mesopotâmia (1985-1989) consiste em duas estantes_Tigre e Eufrates_com mais de cem livros de chumbo em escala maior que a humana. Alguns estão vazios, outros contêm fotografias escuras, folhas secas, areias. Pesadíssimos, difíceis de manusear, se não impossíveis, estão quase a cair das prateleiras, inclinados, tortos; arames de cobre como teias de aranha atravessam as estantes e se pousam sobre os volumes.

Em 1990, Breaking the Vessels / A quebra dos vasos repete o tema da biblioteca. A peça recria um tema cabalístico do século XVI[11], do qual não existe tradição iconográfica (exceto o diagrama conhecido como árvore da vida ou árvore sefirótica). Quarenta e um livros de folhas de chumbo estão dispostos em uma estante de aço, em cujo topo,num semicírculo de vidro,está grafado o nome do Ein Sof, o princípio oculto, o não manifestado, o incompreensível. Os Sephirot, emanações do nome divino, estão escritos em etiquetas aos lados e entre as prateleiras dos livros e se unem por arames de cobre. Estilhaços de vidros se espalham pelo chão e agregam perigo e gravidade à obra. Hierática e solene, a peça se impregna de uma retórica da transcendência que a enlaça com a grande arte religiosa do passado.

Estas instalações _ tinha outra biblioteca na exposição do Grand Palais, Falling stars, 2007_ estão impregnadas de uma fascinação pelas ruínas, não como o resultado de catástrofes, mas como início de renascimento. Menos interessado na fixidez do monumento ou do memorial que nos processos de transformação física ou espiritual, Anselm Kiefer parece 
nos dizer que as ruínas deixam ver o âmago das coisas, sua semente.

Restore Now, 2006, de Thomas Hirschhorn, montada na 27a Bienal de São Paulo e atualmente em exibição em Inhotim, MG, não chega a ser plenamente uma biblioteca, mas nessa obra uma acumulação de objetos diversos, entre eles livros, se oferece como instrumentos para uma interpretação reconstrutiva do mundo. As obras de Hirschhorn são dispositivos cenográficos ativos que se apropriam do espaço numa propagação anárquica: junto dos livros colados e parcialmente inutilizados, há um reservatório de ferramentas desorganizado, mensagens de paz escritas com grandes pregos, fotos de trabalhadores massacrados. Os livros, como armas, amontoam-se no caos. O artista afirma:

\begin{abstract}
Se em "Restore Now" há livros de filosofia ampliados, se há livros de filosofia colados com fita adesiva, se colei ferramentas nos livros de filosofia, se os confrontei com imagens de seres humanos destruídos ou feridos, é para dar forma à afirmação: as ferramentas que estão lá, nós as temos_vamos utilizá-las, utilizemos os martelos, os parafusos, furadeiras, os pé-de-cabra e utilizemos os livros de filosofia_para consertar, bricolar, tampar, construir, mas também para quebrar (as desigualdades), para lutar (contra o racismo, os ressentimentos), para lutar contra (as injustiças), é essa a mensagem de "Restore Now": nós temos as ferramentas (é por isso que a responsabilidade é universal!), passemos à ação![12]
\end{abstract}

Hirschhorn procura se dirigir ao homem comum e impulsioná-lo a agir: a filosofia e a arte podem agir. A força da instalação reside na brutalidade das suas fotos sangrentas, das ferramentas e dos livros canônicos da filosofia ocidental contemporânea agigantados, pregados, amarrados, colados. Se a mensagem do artista quer ser de convite à ação e a revolta, a percepção do visitante é a da iminência de catástrofe e ruína. Nem as ferramentas, nem os livros poderão salvar-nos.

Mais recentemente a jovem artista Marilá Dardot, cujo trabalho se desenvolve quase exclusivamente a partir de palavras, livros e bibliotecas, apresentou uma instalação chamada A biblioteca de Babel, 
2005-2011. A artista criou um ambiente onde estavam esticadas algumas redes; na galeria havia também vasos de samambaias e avencas, esteiras e almofadas no chão. Espalhados, ao redor, caixotes de frutas continham livros que ficavam à disposição dos visitantes. Esses livros foram emprestados por amigos,vizinhos ou,ainda, desconhecidos que acudiram ao pedido da artista: "Há algum livro que você gostaria de compartilhar com o mundo?". Ao serem recebidos, foram fichados e carimbados, registrando que fizeram parte da exposição. Sobre os caixotes havia também dois fichários de madeira com as fichas bibliográficas dessa biblioteca íntima e provisória.

Na 29a Bienal de São Paulo, 2010, a artista realizou, com Fábio Morais, um trabalho denominado Longe daqui, aqui mesmo, concebido como um dos terreiros, espaços participativos da mostra. De acordo com seus criadores

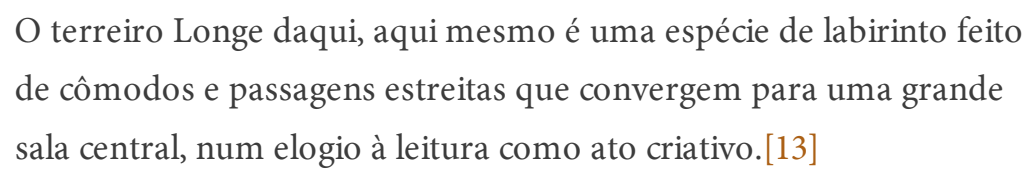

Uma construção precária, de tijolos sem reboco externo, cujas paredes, portas e tapetes estavam cobertos com capas de livros importantes para os artistas. Através do labirinto chegava-se a um espaço central, onde se encontrava a sala de leitura. Alguns pertenciam a uma coleção de livros de artistas enviados de várias partes do mundo, outros foram emprestados como resposta ao convite feito aos participantes da 29a Bienal: Com que livro você construiria sua casa?[14] Bancos e poltronas contribuíam a criar um espaço confortável para se sentar e ler em silêncio.

A maior parte das bibliotecas que enumeramos está morta; seus livros foram queimados, enterrados ou interditados pelo cimento ou pelo chumbo, ou ainda por fitas colantes, pregos e correntes. Bibliotecas impossíveis que nos confrontam com seus próprios espectros calcinados. As últimas, porém, as de Marilá Dardot e Fábio Morais, aparecem como o nascedouro da biblioteca. Em ruínas como as outras, mas também em construção, locais onde tudo é precário, menos os livros, que resistiram 
entre a irmandade e o afeto de muitos. Rebentos de bibliotecas futuras.

\section{CODA}

Existem muitos outros trabalhos que se debruçam sobre as estantes e os livros: a Bibliotheca de Rosangela Rennó, 2003, onde moram álbuns de fotografias familiares, aquelas criaturas das regiões fronteiriças [15], que habitam, para Benjamin, todas as bibliotecas vivas; a Biblioteca para Dibutade de Lais Myrrha, onde apenas sobrevivem sombras de poeira no lugar onde estavam os volumes, ou ainda Partially Buried, 1996, de Renée Green, instalação onde a busca da artista pelos restos do barracão enterrado de Robert Smithson, na Kent State University[16], alegoriza _com livros, fotos e discos de época_sua nostalgia por um passado que ainda permanece, um passado que consegue alcançar o instante presente, apesar do intransponível do intervalo temporal.

A biblioteca, nestes trabalhos, seria o lugar seguro e recolhido onde escutamos as vozes dos que estão distantes ou dos que já não estão. Nunca mais o perfeito studiolo de São Jerônimo, ainda não a torre albarrã de Carlos Argentino Daneri. Apenas um lugar deslocado do mundo cotidiano, aonde possam chegar todas as palavras do mundo, uma de cada vez, murmurando através das páginas dos livros. Mas também um lugar ameaçado pelo fogo, pela água, pelos desastres climáticos ou pelos ataques humanos. Talvez o último reduto de uma pátria perdida.

[1] Busquei a paz em todos os lugares e nunca a encontrei, a não ser num canto com um livro.

[2] Para alguns alegoristas a perdiz alude à verdade de Cristo e o pavão à igreja e a onisciência divina. Sobre o plano onde se pousa o escritório se veem duas plantas em vasos: trata-se de um buxo, que aponta para a fé na Salvação, e um gerânio, símbolo da Paixão de Cristo.

[3] O nome doppelgänger se originou das palavras alemãs doppel (significa duplo, réplica ou duplicata) e gänger (andante, ambulante ou aquele que vaga). Segundo a lenda, é um ser que tem o dom de representar uma cópia idêntica de uma pessoa que ele escolhe ou que passa a acompanhar.

[4] BORGES, Jorge Luis. Obras Completas. Buenos Aires: Losada,1976.p. 618.

[5] Arnt, Sicutenimlibriiuxtaaquas et humorescitoobscurantor, delentur et pereunt... p. 188

[6] FALUDY,Gyorgy.Learn This Poem of Mine by Heart: sixty poems and one speech. Toronto: Hounslow Press, 1983. p.67.

[7] A 10 de maio de 1933, 25 mil livros foram queimados em 34 cidades 
universitárias alemãs, em rituais em que compareceram oficiais nazistas, reitores, professores e estudantes. Fizeram-se listas de escritores tidos como contrários à ideologia nazista, procurou-se fazer das universidades centros nacionalistas. Entregaram-se às chamas os escritos de Heinrich Mann, Ernst Gläser, Erich Kästner, críticos ao regime, e as obras de socialistas como Bertolt Brecht e Karl Marx, mas também escritores como Erich Maria Remarque, Heinrich Heine, Ernest Hemingway, Jack London e Helen Keller, "influências estrangeiras corruptoras", e até Albert Einstein, alemão de origem judia, Nobel da Física em 1921.

[8] Num artigo publicado no Harper's magazine, em dezembro de 2001, Nas ruínas do futuro, Don DeLillo vê o atentado contra o WTC como sintoma de uma doença religiosa, tecnológica, moral e econômica: a guerra entre o passado e o futuro. $\mathrm{O}$ atentado parece ter corrompido definitivamente nossa relação com o futuro, afirma: agora tratamos de dar nome ao futuro não com a atitude habitual de esperança, mas impulsionados pelo medo. Esse futuro em ruínas modificaria a história: pois a civilização do futuro está ameaçada por um estado teocrático sem confins, flutuante e obsoleto até o ponto de depender do fervor dos suicidas para alcançar seus objetivos.

[9] http://www.theguardian.com/profile/adriansearle

(http://www.theguardian.com/profile/adriansearle)

[10] BRODSKY, Marcelo. Nexo. Buenos Aires: La Marca, 2001. p.77.

[11] De acordo com Isaac Luria, o Ein Sof realiza um movimento, contrário, de concentração em si mesmo, abrindo espaço para a emanação de seus atributos, numa estrutura hierárquica de esferas de luz, as dez sefirot ou emanações. Cada sefirot tem seu vaso, que preserva a luz divina. A shevirathakelim (quebra dos vasos) é uma convulsão cósmica, que rompe os vasos que abrigavam as luzes das últimas sefirot. Cf. SHOLEM, Gerhard. On the Kabbalah and it simbolisms. New York, Schocken Books, 1969. p.112.

[12] LAGNADO,Lisette: "É preciso trabalhar para lutar contra o politicamente correto e a má consciência” Revista Trópico,

http://p.php.uol.com.br/tropico/html/textos/2803,1.shl

(http://p.php.uol.com.br/tropico/html/textos/2803,1.shl)

[13] Catálogo da 29a Bienal de São Paulo. São Paulo, 2010. p. 340.

[14] Idem.

[15] BENJAMIN, Walter. Rua de Mão única. Obras Escolhidas II. São Paulo, Brasiliense, 1993. p. 234.

[16] Partially Burried in Three Parts (1996-1999) enlaça vários estratos de memórias como as ruínas de Partially burried Woodshed, de Robert Smithson, e a matança de estudantes pela Guarda Nacional em Kent State University, em 1970. Cf. SMITH, Terry, ENWEZOR, Okwui\& CONDEE, Nancy (Editors) Antinomies of Artand Culture. Durham \&London: Duke University Press, 2008. p. 324-334

MARIA ANGÉliCA MELENDi é professora da Escola de Belas Artes da Universidade Federal de Minas Gerais e coordenadora do Grupo de Pesquisa Estratégias da Arte na Era das Catástrofes (www.estrategiasarte.net.br (http://www.estrategiasarte.net.br). 